\title{
Analysis of the Probability of Acceptance of the Normality Hypothesis by the Goodness-of-Fit Tests
}

\author{
Ramona CLINCIU \\ Transilvania University of Brasov, Romania, r.clinciu@unitbv.ro
}

\begin{abstract}
The paper presents and emphasizes the behaviour of different goodness-of-fit tests, towards the acceptance of the normality hypothesis. The goodness of fit tests considered are general goodness-of-fit tests - KolmogorovSmirnov, Cramer-von-Mises, Anderson-Darling, and normality goodness-of-fit tests - Lilliefors, Shapiro-Wilk, D'Agostino, Massey, Filliben, Z, Cox. These goodness-of-fit tests are conducted on normally distributed data in order to test the normality of the data. The need for testing the normality of the data appears especially in metrology, for the analysis of the metrological reliability. General metrology uses especially the normal distribution, despite the fact that positive and asymmetrical distributions (e.g. Weibull distribution) are frequently met in the analysis of the metrological reliability. In these cases, it is necessary to perform goodnessof-fit tests in order to ascertain that the normal distribution fits the data. The quality of the results depends on the goodness-of-fit test which was chosen to determine if the normal distribution fits the data best.
\end{abstract}

\section{Keywords}

metrological reliability, goodness-of-fit tests, normal distribution

\section{Introduction}

Goodness-of-fit tests are essential for the quantitative evaluation of a system reliability and maintainability. The most important issue for data analysis is to find the best, or the most appropriate distribution which describes the experimental collected data and goodness-of-fit tests are used to test whether the selected distribution fits the data.

Positive and asymmetrical distributions (e.g. Weibull distribution) are met frequently in the analysis of the metrological reliability. Despite this fact, metrology uses especially the normal distribution and, in these cases, it is necessary to perform goodness-of-fit tests in order to ascertain that the normal distribution fits the data [1]. The quality of the results obtained depends on the goodness-of-fit test which was chosen to test if the normal distribution fits the data best.

The present paper aims to present and emphasize the results obtained by conducting different goodness-of-fit tests on normally distributed data, in order to test the probability of acceptance of the normality hypothesis by the goodness-of-fit tests which were considered: general goodness-of-fit tests - Kolmogorov-Smirnov, Cramer-von-Mises, Anderson-Darling, and normality goodness-of-fit tests Lilliefors, Shapiro-Wilk, D'Agostino, Massey, Filliben, Z, Cox. These tests are conducted on normally distributed data grouped in samples of different sizes, in order to test the normality of the data. Their behaviour towards the considered samples, generated according to the normal distribution function is to be studied. The goodness-of-fit tests considered in this research were applied in accordance with the speciality literature [1-9]. Although in [7] Cox goodness-of-fit test is considered to be adequate for $\mathrm{n}>100$, it was conducted on small sizes of samples too, in order to analyse its behaviour towards the small sizes of samples. The results are presented in this paper. Goodness of fit tests are applied in researches $[10,11,12]$ in order to test the normality of data.

The general goodness-of-fit tests were used in their modified form, according to the situation in which the parameters of the normal distribution are not known and they need to be estimated by $[2,3]$ :

$$
\begin{gathered}
m=\frac{1}{n} \sum_{i=1}^{n} x_{i} \\
\sigma=\sqrt{\frac{1}{n-1} \sum_{i=1}^{n}\left(x_{i}-m\right)^{2}}
\end{gathered}
$$


where $x_{i}, i=1, \ldots n$, are the values in the sample, $n$ is the size of the sample, $m$ is the mean, and $\sigma$ is the standard deviation.

\section{Case Study: Programmed Generation of Normally Distributed Data}

In this case study, the considered goodness-of-fit tests were performed on normally distributed data, data being obtained by programmed generation according to the formulas below $[4,5,6]$ :

$$
\begin{gathered}
x_{i}=m \pm z_{i} \cdot \sigma, \quad i=1, \ldots, n \\
z_{i}=\mathrm{F}^{-1}\left(\alpha_{i}\right) \\
\alpha_{i}=\frac{i-3 / 8}{n+1 / 4}, \quad i=1, \ldots, n \\
F(z)=\frac{1}{2 \cdot \pi} \int_{0}^{z} e^{-\frac{t^{2}}{2}} d t
\end{gathered}
$$

The tests were conducted on samples with different sizes $n \in\{5,10,20,30,40,50,60,80,100\}$, each sample being generated according to the equation (3).

Table 1 and Table 2 present the results of the tests in the case the considered samples are normally

\begin{tabular}{|c|c|c|c|c|c|}
\hline Sample size $(n)$ & 5 & 10 & 20 & 30 & 40 \\
\hline \multicolumn{6}{|c|}{ General goodness-of-fit tests / decision criteria } \\
\hline $\begin{array}{c}\text { Kolmogorov - Smirnov } \\
\left(\mathrm{d} \leq \mathrm{d}_{n, \alpha}\right)\end{array}$ & $\begin{array}{c}0.2872< \\
0.895\end{array}$ & $\begin{array}{c}0.1989< \\
0.895\end{array}$ & $\begin{array}{c}0.1407< \\
0.895\end{array}$ & $\begin{array}{c}0.1238< \\
0.895\end{array}$ & $\begin{array}{c}0.1075< \\
0.895\end{array}$ \\
\hline $\begin{array}{c}\text { Cramer-von-Mises } \\
\left(\mathrm{W}^{2}<\mathrm{W}^{2} n, \alpha\right)\end{array}$ & $\begin{array}{c}0.0186< \\
0.126\end{array}$ & $\begin{array}{c}0.009< \\
0.126\end{array}$ & $\begin{array}{c}0.0045< \\
0.126\end{array}$ & $\begin{array}{c}0.0031< \\
0.126\end{array}$ & $\begin{array}{c}0.0024< \\
0.126\end{array}$ \\
\hline $\begin{array}{c}\text { Anderson-Darling } \\
\left(\mathrm{A}^{2}<\mathrm{A}^{2}{ }_{n, \alpha}\right)\end{array}$ & $\begin{array}{c}0.105< \\
0.787\end{array}$ & $\begin{array}{c}0.0899< \\
0.787\end{array}$ & $\begin{array}{c}0.0521< \\
0.787\end{array}$ & $\begin{array}{c}0.037< \\
0.787 \\
\end{array}$ & $\begin{array}{c}0.029< \\
0.787 \\
\end{array}$ \\
\hline \multicolumn{6}{|c|}{ Normality goodness-of-fit tests / decision criteria } \\
\hline $\begin{array}{l}\text { Lilliefors } \\
\left(\mathrm{L} \leq \mathrm{L}_{n, \alpha}\right)\end{array}$ & $\begin{array}{c}0.1102< \\
0.337\end{array}$ & $\begin{array}{c}0.0581< \\
0.258\end{array}$ & $\begin{array}{c}0.0302< \\
0.190\end{array}$ & $\begin{array}{c}0.0167< \\
0.161\end{array}$ & $\begin{array}{c}0.0167< \\
0.1401\end{array}$ \\
\hline $\begin{array}{c}\text { Shapiro-Wilk }(3<n<50) \\
\left(\mathrm{W} \geq \mathrm{W}_{n, \alpha}^{2}\right)\end{array}$ & $\begin{array}{c}0.9965> \\
0.986 \\
\end{array}$ & $\begin{array}{c}0.9966> \\
0.978 \\
\end{array}$ & $\begin{array}{c}0.9972> \\
0.983 \\
\end{array}$ & $\begin{array}{c}0.9961> \\
0.985 \\
\end{array}$ & $\begin{array}{c}0.9949> \\
0.987 \\
\end{array}$ \\
\hline $\begin{array}{l}\text { D'Agostino }(n>50) \\
Y \in\left(Y_{n, \alpha / 2}, Y_{n, 1-\alpha / 2}\right)\end{array}$ & - & - & - & - & - \\
\hline $\begin{array}{c}\text { Massey }(10<\mathrm{n}<30) \\
\left(\mathrm{d} \leq \mathrm{d}_{n, \alpha}\right)\end{array}$ & - & $0.0689<0.130$ & $\begin{array}{c}0.0364< \\
0.117\end{array}$ & $\begin{array}{c}0.026< \\
0.102\end{array}$ & - \\
\hline $\begin{array}{c}\text { Filliben } \\
\left(r_{c} \geq r_{n, \alpha}\right)\end{array}$ & $1>0.995$ & $1>0.99$ & $\begin{array}{c}0.9999> \\
0.992\end{array}$ & $1>0.994$ & $1>0.995$ \\
\hline $\begin{array}{c}\mathrm{Z} \\
\left(\mathrm{Z} \leq \mathrm{Z}_{n, \alpha}\right)\end{array}$ & $\begin{array}{c}0.0088< \\
1.4047\end{array}$ & $0<0.8744$ & $0<0.6135$ & $0<0.5045$ & $0<0.4392$ \\
\hline $\begin{array}{c}\operatorname{Cox}\left(b_{1} / b_{2}\right) \\
b_{1} \in[-0.05,0.05] \\
b_{2} \in[2.95,3.05]\end{array}$ & $\begin{array}{c}0.0074 / \\
1.8547\end{array}$ & $0 / 2.1855$ & $0 / 2.4314$ & $0 / 2.5391$ & $0 / 2.6089$ \\
\hline
\end{tabular}
distributed, being obtained by programmed generation of normally distributed data, the parameters of the normal distribution being $m=0$ and $\sigma=1$.

Table 1. Tests statistics and their critical values

By analysing the results indicated in Tables 1 and Table 2, the conclusion is that all the considered goodness-of-fit tests accept the normal hypothesis of the programmed distribution, except for the Cox 
RECENT, Vol. 19, no. 3(56), December, 2018

goodness-of-fit test for parameter $b_{2}$.

Table 2. Tests statistics and their critical values

\begin{tabular}{|c|c|c|c|c|}
\hline Sample size (n) & 50 & 60 & 80 & 100 \\
\hline \multicolumn{5}{|c|}{ General goodness-of-fit tests / decision criteria } \\
\hline $\begin{array}{c}\text { Kolmogorov - Smirnov } \\
\left(\mathrm{d} \leq \mathrm{d}_{n, \alpha}\right)\end{array}$ & $0.0968<0.895$ & $0.0952<0.895$ & $0.0862<0.895$ & $0.0808<0.895$ \\
\hline $\begin{array}{c}\text { Cramer-von-Mises } \\
\left(\mathrm{W}^{2}<\mathrm{W}^{2} n, \alpha\right)\end{array}$ & $0.002<0.126$ & $0.0017<0.126$ & $0.0013<0.126$ & $0.0011<0.126$ \\
\hline $\begin{array}{c}\text { Anderson-Darling } \\
\left(\mathrm{A}^{2}<\mathrm{A}_{n, \alpha}^{2}\right)\end{array}$ & $0.0243<0.787$ & $0.021<0.787$ & $0.0166<0.787$ & $0.0138<0.787$ \\
\hline \multicolumn{5}{|c|}{ Normality goodness-of-fit tests / decision criteria } \\
\hline $\begin{array}{l}\text { Lilliefors } \\
\left(\mathrm{L} \leq \mathrm{L}_{n, \alpha}\right)\end{array}$ & $0.0135<0.1253$ & $0.0121<0.1144$ & $0.0095<0.0991$ & $0.008<0.0886$ \\
\hline $\begin{array}{c}\text { Shapiro-Wilk }(3<n<50) \\
\left(\mathrm{W} \geq \mathrm{W}^{2} n, \alpha\right)\end{array}$ & $0.9935>0.988$ & - & - & - \\
\hline $\begin{array}{l}\text { D'Agostino }(n>50) \\
Y \in\left(Y_{n, \alpha / 2}, Y_{n, 1-\alpha / 2}\right)\end{array}$ & $\begin{array}{c}0.4322 \in \\
(-2.2,0.923)\end{array}$ & $\begin{array}{c}0.4297 \in \\
(-2.179,0.986)\end{array}$ & $\begin{array}{c}0.4036 \in \\
(-2.118,1.076)\end{array}$ & $\begin{array}{c}0.3874 \in \\
(-2.075,1.137)\end{array}$ \\
\hline $\begin{array}{c}\text { Massey }(10<n<30) \\
\left(\mathrm{d} \leq \mathrm{d}_{n, \alpha}\right)\end{array}$ & - & - & - & - \\
\hline $\begin{array}{c}\text { Filliben } \\
\left(\mathrm{r}_{\mathrm{c}} \geq \mathrm{r}_{n, \alpha}\right) \\
\end{array}$ & $1>0.996$ & $1>0.996$ & $1>0.997$ & $1>0.998$ \\
\hline $\begin{array}{c}\mathrm{Z} \\
\left(\mathrm{Z} \leq \mathrm{Z}_{n, \alpha}\right)\end{array}$ & $0<0.3943$ & $0<0.3609$ & $0<0.3137$ & $0<0.2812$ \\
\hline $\begin{array}{c}\operatorname{Cox}\left(b_{1} / b_{2}\right) \\
b_{1} \in[-0.05,0.05] \\
b_{2} \in[2.95,3.05]\end{array}$ & 0 / 2.6496 & $0 / 2.6815$ & $0 / 2.7349$ & $0 / 2.7688$ \\
\hline
\end{tabular}

\section{Case Study: Random Generation of Normally Distributed Data}

Two methods were used for random generation of normally distributed data. In the first method used for random generation of normally distributed data, $n$ uniform random variables $Q_{i}, i=1, \ldots, n$, are generated and then, variable $t$ is calculated according to [8]:

$$
\begin{gathered}
t=\sqrt{\ln \frac{1}{Q^{2}}} \\
Q= \begin{cases}Q & 0<Q \leq 0.5 \\
1-Q & 0.5<Q<1\end{cases}
\end{gathered}
$$

Random variables having a normal distribution can be generated by [8]:

$$
x=t-\frac{c_{0}+c_{1} \cdot t+c_{2} \cdot t^{2}}{1+d_{1} \cdot t+d_{2} \cdot t^{2}+d_{3} \cdot t^{3}}+\varepsilon(Q),
$$

where the error $\varepsilon(Q)$ is given by (10) and the constants are given by (11) [8]:

$$
\begin{aligned}
& |\varepsilon(Q)|<4.5 \cdot 10^{-4} \\
& c_{0}=2.515517 \quad d_{1}=1.432788 \\
& c_{1}=0.802853 \quad d_{2}=0.189269 \\
& c_{2}=0.010328 \quad d_{3}=0.001308
\end{aligned}
$$

The second method used for random generation of normally distributed data is the one derived from the central limit theorem. According to this method, random variables having a normal distribution can be generated by [3]: 


$$
x=\sum_{i=1}^{12} U_{i}-6,
$$

where $U_{i}, i=1, \ldots, n$, are uniform random variables.

The tests have been conducted on samples with different sizes $n \in\{5,10,20,30,40,50,60,80,100\}$ in each case being considered 2000 samples of each size $n$. The samples were generated according to the equation (9) or (12), respectively, and the considered goodness-of-fit tests were performed on the samples.

Tables 3 and 4 present the results obtained in case the samples were generated according to both equations (9) and (12) - the probability of acceptance, in percentage, of the normality hypothesis by the goodness-of-fit tests which were considered.

The adopted significance level is $\alpha_{\mathrm{ad}}=0.05$.

Table 3. Probability of acceptance of the normality hypothesis

\begin{tabular}{|c|c|c|c|c|c|}
\hline Sample size $(n)$ & 5 & 10 & 20 & 30 & 40 \\
\hline \multicolumn{7}{|c|}{ Samples generated according to equation (9) / Samples generated according to equation (12) } \\
\hline \multicolumn{7}{|c|}{ General goodness-of-fit tests } \\
\hline Kolmogorov - Smirnov & $95.5 / 94$ & $95 / 95$ & $96 / 91$ & $95.5 / 95$ & $96 / 96$ \\
\hline Cramer-von-Mises & $95 / 97$ & $96.5 / 96$ & $96 / 93$ & $98 / 95$ & $94 / 96$ \\
\hline Anderson-Darling & $99 / 98$ & $95.3 / 92$ & $93.8 / 94$ & $95 / 95$ & $95.4 / 96$ \\
\hline \multicolumn{7}{|c|}{ Normality goodness-of-fit tests } \\
\hline Lilliefors & $97 / 98$ & $97 / 96$ & $97 / 96$ & $97 / 97$ & $97 / 97$ \\
\hline Shapiro-Wilk (3<n<50) & $5 / 0$ & $5.1 / 5$ & $4.5 / 5$ & $5.9 / 7$ & $5.4 / 6$ \\
\hline D'Agostino $(n>50)$ & - & - & - & - & - \\
\hline Massey (10<n<30) & - & $28 / 25$ & $54.6 / 51$ & $60.6 / 55$ & - \\
\hline Filliben & $2.7 / 0$ & $4.1 / 1.4$ & $6.4 / 6$ & $5.4 / 5$ & $6 / 6$ \\
\hline $\mathrm{Z}$ & $92 / 96$ & $91 / 95$ & $90 / 89$ & $91 / 85$ & $90 / 87$ \\
\hline Cox $(n>100)$ & $0 / 0.1$ & $0.1 / 0.1$ & $0.2 / 0.2$ & $0.5 / 0.5$ & $0.6 / 0.6$ \\
\hline
\end{tabular}

Table 4. Probability of acceptance of the normality hypothesis

\begin{tabular}{|c|c|c|c|c|}
\hline Sample size $(n)$ & 50 & 60 & 80 & 100 \\
\hline \multicolumn{5}{|c|}{ Samples generated according to equation (9)/ Samples generated according to equation (12) } \\
\hline \multicolumn{5}{|c|}{ General goodness-of-fit tests } \\
\hline Kolmogorov - Smirnov & $95.5 / 93$ & $95 / 96$ & $95.5 / 97$ & $96 / 96$ \\
\hline Cramer-von-Mises & $95 / 92$ & $95 / 93$ & $96 / 95$ & $95 / 93$ \\
\hline Anderson-Darling & $98 / 92$ & $95 / 95$ & $95 / 94$ & $95 / 93$ \\
\hline \multicolumn{5}{|c|}{ Normality goodness-of-fit tests } \\
\hline Lilliefors & $97 / 97$ & $97 / 97$ & $97 / 98$ & $97 / 98$ \\
\hline Shapiro-Wilk (3<n<50) & $4.8 / 4$ & - & - & - \\
\hline D'Agostino (n>50) & $90 / 93$ & $90 / 92$ & $90 / 90$ & - \\
\hline Massey (10<n<30) & - & - & - & $3 / 4$ \\
\hline Filliben & $3.4 / 3$ & $7 / 7$ & $6 / 7$ & $92 / 92$ \\
\hline $\mathrm{Z}$ & $90 / 97$ & $90 / 93$ & $93 / 92$ & $1.75 / 1.5$ \\
\hline Cox (n>100) & $0.85 / 0.6$ & $0.9 / 0.7$ & $1.35 / 1.4$ & \\
\hline
\end{tabular}

\section{Conclusions}

The analysis of the results obtained in this research indicates the fact that the probability of acceptance of the normality hypothesis in case of applying the normality goodness-of-fit tests is 
smaller than the probability of acceptance of the normality hypothesis in case of the general goodnessof-fit tests.

Another conclusion drawn is that, among the normality goodness-of-fit tests, the smallest values for the probability of acceptance of the normality hypothesis are obtained in case the Cox or Filliben goodness-of-fit tests are conducted. The greatest values for the probability of acceptance of the normality hypothesis are obtained in case of application of Z, D'Agostino and Lilliefors goodness-of-fit tests, these values being comparable to those obtained in case general goodness-of-fit tests are conducted.

The results obtained in the research described in the present paper indicate the fact that the probability of acceptance of the normality hypothesis by the goodness-of-fit tests increases with the size of the sample in most cases.

\section{References}

1. Vodă V.Gh. (1979): Metode de testare a normalității datelor de măsurare (Methods for testing the normality of the measuring data). Metrologia aplicată, nr. XXVI (1), p. 11-14 (in Romanian)

2. Craiu V., Enache R., Basca O. (1988): Teste de concordanţă cu programe în FORTRAN (Goodness of fit tests with programmes in FORTRAN). Editura Știinţifică şi Enciclopedică, București, Romania (in Romanian)

3. Kececioglu D. (1991): Reliability Engineering Handbook. Prentice Hall, 1st ed., ISBN 978-0137722945

4. Iliescu D.V., Vodă V.Gh. (1977): Statistică şi toleranţe (Statistics and tolerances). Editura Tehnică, București, Romania (in Romanian)

5. Martinescu I., Popescu I. (1995): Fiabilitate (Reliability). Gryphon, ISBN 973-604-007-0, Brasov, Romania (in Romanian)

6. Wiener U., Isaic-Maniu A., Vodă V.Gh. (1983): Aplicaţii ale rețelelor probabiliste în tehnică (Applications of the probabilistic networks in technique). Editura Tehnică, București, Romania (in Romanian)

7. Motoiu R. (1994): Ingineria calităţii (Quality Engineering). Editura Chiminform Data, București, Romania (in Romanian)

8. Hewlett-Packard HP-25 (1975): Application Programs. Hewlett-Packard Company

9. Bentley J. (1993): An Introduction to Reliability and Quality Engineering. John-Wiley\& Sons Inc., ISBN 9780201331325, New York

10. Clinciu R. (2013): Determining the Calibration Life of Measuring Devices by Means of Parameter Deviation Function. Applied Mechanics and Materials, ISSN 1660-9336, No. 371, p. 695-699, DOI: 10.4028/www.scientific.net/AMM.371.695

11. Clinciu M.R. (2011): Statistical Analysis of Data Samples Collected in an Experimental Installation. Bulletin of the Transilvania University of Brasov, Series I, ISSN 2065-2119, Vol. 4(53), no. 1, p. 25-30

12. Clinciu R., Clinciu M.R. (2018): Study on the Metrological Reliability of Water Meters. IOP Conference Series Materials Science and Engineering, vol. 399(1), p. 012009, DOI: 10.1088/1757-899X/399/1/012009, https://www.researchgate.net/publication/328050309 Study on the metrological reliability of the water meters 